\title{
Eros digital y su síntoma.
}

\section{Digital Eros and its symptom.}

DOI: $10.32870 /$ sincronia.axxv.n80.9b21

\author{
Amorhak Ornelas Vázquez \\ Universidad del Claustro de Sor Juana (MÉXICO) \\ CE: xavier.ornelasv@universidaddelclaustro.edu.mx / ID ORCID: 0000-0003-2153-8435
}

Esta obra está bajo una Licencia Creative Commons Atribución-NoComercial 4.0 Internacional

Recibido: 31/03/2021

Revisado: 04/05/2021

Aprobado: 18/05/2021

\section{RESUMEN}

En este trabajo se expondrán algunos ejes que conforman la digitalización de la vida amorosa y ciertos síntomas que provocan el uso de las nuevas tecnologías. Procedo en cuatro coordenadas: primero parto en explicar el ingreso de la vida afectiva al espacio digital, luego desarrollo el concepto de capital sexual, posteriormente menciono lo que es una nueva escritura de Eros y finalmente analizo lo que es el uso sintomático de las nuevas tecnologías.

Palabras claves: Eros. Digital. Capital sexual. Nuevas tecnologías.

\section{ABSTRACT}

In this paper i present some axes that make up the digitization of love lifestyle and certain symtoms that cause the use of the new technologies. I proceed in four coordinates: firts $i$ start by explaining the entry of affective life into the digital space, then i develop the concept of sexual capital, later i mention what is a new writing of Eros and finally $i$ analyze what is the symptomatic use of new technologies.

Keywords: Eros. Digitization. Sexual capital. New technologies. 
El amor nos interroga, como ha sucedido desde la Grecia antigua con el Banquete de Platón, también a principios del siglo XX con la invención del psicoanálisis y la noción de transferencia hechos por Sigmund Freud y ahora con el uso de las nuevas tecnologías para encontrar pareja. Al respecto, el psicoanalista francés Jacques Lacan (2003), en el comentario que hace sobre el Banquete en su seminario sobre La transferencia, señalaba que un efecto de este diálogo es lo que se llama el agalma, que es el tesoro que no se ve. El agalma se trata de un objeto que genera encanto, y para Lacan, este es producto del efecto de significación en el objeto, funda su valor de ser algo postizo y sobre todo, genera una moda y fascinación. Exactamente como ahora nos sucede con las las selfis, los blogs, los canales de YouTube o los perfiles de Facebook, Instagram, Tik Tok. Cada época tiene su Ars amandi (arte de amar) que expone y desarrolla las condiciones en las que el amor se dice y actúa. En la época clásica encontrábamos a Ovidio, en la romántica a Stendhal; y en nuestros días las aplicaciones para citas como Tinder. Estas condiciones nos llevan a plantear una serie de interrogantes: ¿cómo incide esta nueva realidad digital en la subjetividad de los individuos del siglo XXI?, ¿qué tipo de deseo y de amor el ciberespacio impulsa en nosotros?, ¿cómo es el uso sintomático que tenemos con las nuevas tecnologías? Para abordar estas cuestiones, voy a destacar cuatro ejes que considero cruciales para el análisis de la digitalización de Eros, y que son: la digitalización de la vida afectiva, el capital sexual, la nueva escritura de Eros y los usos sintomáticos de las nuevas tecnologías.

\section{La digitalización de la vida afectiva}

Que las tecnologías de comunicación e información están modificando nuestras vidas en el plano físico, intelectual y emocional, es una afirmación que se ha convertido en una de las más recurrentes de nuestra época, y por lo mismo, quizás sea de la que más tengamos que sospechar. No porque sea una afirmación falsa, sin fundamentos o que sea parte de las neofobias que surgen cuando accedemos a un avance tecnológico - como sucedió con la imprenta de Gutenberg, la fotografía, el fonógrafo, la teoría de Heisenberg y ahora el internet-, sino porque quizás no nos 
explica nada. ¿Qué es lo nuevo ahora con la digitalización? En el plano del amor y el sexo, efectivamente los dispositivos móviles, las aplicaciones y las redes sociales digitales, se han convertido en un medio que sustituye a los territorios urbanos de placer ritual donde eros tenía su lugar (parques, discotecas, bares). Eros se ha desplazado a la tactilidad de las pantallas, tomando propiedades eléctricas, digitales y sobre todo, convirtiéndose en un espectáculo. A propósito del espacio digital, Byung-Chul Han (2014) señala que "La palabra digital refiere al dedo (digitas), que ante todo cuenta. La cultura digital descansa en los dedos que cuentan. Historia, en cambio, es narración. Ella no cuenta" (p.60). Ahora los seres hablantes se seducen, se aman, se excitan, se pelean e incluso tienen sus rupturas a través de la escritura digital. Y esto es así, porque el espacio digital se ha convertido para muchas personas, en un lugar más confortable, ligero y paliativo, que el que encuentran en la realidad cotidiana. La digitalización tiene la propiedad de reducir las resistencias y desaparecer aquello que percibimos como negativo. En la sociedad paliativa en la que nos hemos convertido, como lo señala Han (Byung-Chul, 2021) "La digitalización es una anestesia" (p. 52). Efectivamente, el espacio digital nos da la ilusión de que la alteridad dolorosa pude desaparecer y suprimirse en el amor, manteniendo al otro a la distancia que uno quiera. Un eros sin riesgo, sin dolor y confortable, es lo que la digitalización promueve.

\section{El capital sexual}

Para aproximarnos a la cuestión de Eros digital, quiero retomar un enfoque introducido recientemente por dos sociólogas. Illouz y Kaplan (2020) hablan de capital sexual, para para referirse a "la capacidad que tienen algunos sujetos de aumentar el valor personal y obtener beneficios económicos de sus propias capacidades sexuales" (p.65). Resulta que, en la modernidad tardía, a medida que la esfera de la producción queda subsumida bajo la acumulación del capital, el capital sexual se convierte en un camino para convocar, representar, exhibir y actualizar la subjetividad sexual de un modo que maximice el valor personal. Lo que sostienen las sociólogas, es que su enfoque de capital sexual: 
[...] ya no considera al sexo y la sexualidad como el núcleo oculto de un yo auténtico. Más bien, el sexo y la sexualidad se han vuelto mensurables y objetivados como elecciones de estilo de vida y de identidad, como habilidades y técnicas improbables, como modos de comunicación personal, caminos hacia el bienestar y evidencia de creatividad, experiencia y singularidad manifiestas (pp. 60-61).

Sin embargo, su enfoque del capital sexual no supone el de ser un acto racionalizado, donde el sexo funciona como un capital individualista para satisfacer intereses individuales, sino que el capital sexual serviría como recurso para obtener una ventaja en mercadas laborales cada vez más competitivos (p. 73). El caso de las selfis, son una manera en que ponemos en operación nuestro capital sexual y narcisismo, para convertir nuestra intimidad amorosa en un espectáculo. El psicoanalista español José Ubieto (2019) señala:

El éxito de las selfis - así como de los tatuajes - nos habla de esa búsqueda permanente de la marca en el otro, en este caso vía imagen. De la pasión por verse, ante la incertidumbre de la nominación del ser. Las identidades estables son sustituidas por las identidades temporales, en serie. Esa búsqueda insistente no excluye el más allá del principio del placer, de ahí el riesgo de su realización que a veces implica la propia desaparición, lo que hace de la pasión más bien una tiranía (p.116).

Esta pasión por las imágenes y la contemplación de las pantallas nos habla de una alienación con el Otro digital, que puede resultar en algunos casos bastante imperativo, persecutorio y atroz. En el afán de obtener más notificaciones, likes y mensajes, algunos jóvenes han llegado a comportamientos extremos: desde operarse la dentadura, el rostro o los senos con el objetivo de salir mejor en las fotos, hasta los que han perdido la vida por tomarse una selfi en situaciones riesgo (balcones y azoteas de edificios, autos en alta velocidad) ${ }^{1}$. Es indudable que la noción que introdujo Freud (1914) de narcisismo es indispensable para comprender la función de la selfi en nuestra era digital, ya que resulta ser un componente estructural del aparato psíquico, principalmente en lo que

\footnotetext{
${ }^{1}$ https://www.milenio.com/virales/mujer-cae-de-edificio-por-intentar-tomarse-una-selfie
} 
es la formación del yo. Han (Byung-Chul, 2021) afirma que "La sociedad paliativa es además una sociedad del 'me gusta'. Es víctima de un delirio por la complacencia. Todo se alisa y pule hasta que resulte agradable. El like es el signo y también el analgésico del presente" (p. 14). A propósito de la manera en que el Yo se alimenta del culto narcisista en el espacio digital, Gustavo Dessal (2019) menciona:

La posibilidad de convertirse en el protagonista de una serie sin argumento alguno, que no requiere gastos de producción y que sólo permite lograr en muchos casos una considerable audiencia sino también un flujo de dinero, es algo demasiado tentador para el yo. (p.188).

Efectivamente, esto es algo que podemos constatar con la aparición masiva de bloggers, youtubers e influencers, que generan una economía a partir de sus fotos, videos y opiniones que emiten cada día.

\section{La nueva escritura de Eros}

Eloy Fernández Porta (2010), ha sugerido una nueva escritura de Eros, la cuál sería “€®0\$” (p.9). Fernández Porta nos explica que la propuesta de escribir Eros con estas siglas, es porque estas "conforman la secuencia conceptual, discursiva y material que tiene lugar en las relaciones contemporáneas, ya sean pasionales o amistosas, ya sean eróticas o sólo afectuosas" (p.9).

El signo de la moneda euro representa el momento histórico donde ocurren las relaciones de producción, que es el mundo hipercomsumista (p.9). La segunda sigla, que es la de marca registrada representa un sujeto distintivo, el protagonista de ese mundo hipercomsumista, donde la individualidad es reformulada como marketing, entendido como expresión del yo y como búsqueda emocional y publicitaria del Otro (p. 10). La tercera que es el número cero, que es la presencia de un valor contrapuesto a los valores financieros. Ese valor es psicológico, sensitivo, espiritual, y sobre todo, afectivo. El cero es también un hueco, un redondel entorno al vacío. Ese vacío es lo que conocemos como la intimidad. Sin ese hueco no hay dólar, euro, ni marcas registradas. Sin él no hay 
transferencias emocionales, ni sentidos, ni sentido (pp. 10-11). Y la cuarta, el signo del dólar, no es sólo la variante de la primera, sino que, dentro de esa dinámica, representa su dimensión transferencial, intercambiable o relacional. Como afirma Fernández Porta "De la misma manera, las relaciones afectivas suceden bajo el signo de la transferencia, del intercambio: traducción de valores, financieros y sensitivos de un sistema de valor otro" (p.11). Esta nueva escritura de Eros, es muy similar a lo que Freud (1900) Ilamó como condensación en el trabajo del sueño. La condensación es el mecanismo por el cual una representación inconsciente concentra los elementos de una serie de otras representaciones. Y como el sueño es una Bilderschrift, una escritura por imágenes, éstas no deben ser leídas por su valor de imagen, sino que deben de ser tomadas una por una, en lo que Freud Ilama Zeichenbeziehung, es decir, unas relaciones de signos. En ese sentido, la escritura de $€^{\circledR} 0 \$$, condesa lo que es el capital sexual y las emociones, como mercancías que dominan las sociedades capitalistas de nuestros días.

\section{Los usos sintomáticos de las nuevas tecnologías}

Eros digital nos lleva a una ficción de sucumbir a la seducción de una erótica totalmente bajo control, que pueda optimizarse técnicamente. Un erotismo pret à porter, a gusto del consumidor, personalizado, moldeable y programado a la medida de cada quién. Cuando hablo de un Eros digitalizado, implica que este se ha transformado en el lenguaje del capital, es decir, en el lenguaje del rendimiento, lo contable y la eficiencia. Paula Sibilia (2012) señala que las nuevas tecnologías imponen una subjetividad instantánea, en donde los blogs, los perfiles de Facebook, Instagram, Tik Tok, Sanpchat, Tinder, y Youtube, sirven como "Pompeyas multicolores que se suceden una tras otra, donde se ve una secuencia de episodios de la vida cotidiana y de la supuesta intimidad, todos relatados en el tiempo presente de la primera persona del singular" (p. 162). La nueva realidad digital ofrece esta posibilidad de renacer y reinventarse, no sólo en otro diseño gráfico más atractivo y actualizado, sino con perfiles diferentes. La digitalización de eros lleva a una producción masiva de imágenes y contenidos, y que, desde el uso de las nuevas tecnologías, ha generado la comercialización del sexo online. El caso del servicio de suscripción Onlyfans, es un ejemplo de la 
comercialización de un yo que es públicamente sexual y que sirve para la mercantilización de los cuerpos y el sexo. A partir de estas condiciones, vemos configurarse cada vez más, una subjetividad sexual determinada por la lógica de las relaciones de mercado. En el momento en que los individuos deben escoger lo que son, hacen y quieren sexualmente, se transformaran en un nuevo producto, comercializado y disponible para comprarse. Al respecto, es cada vez más frecuente que en la práctica analítica, que escuchemos las vicisitudes de esta erótica digital, que se encuentra bajo las coordenadas del capital sexual, en donde los sujetos piensan su vida íntima desde los criterios del mercado y ciertos ideales. Lo que nos lleva al siguiente cuestionamiento, ¿es posible encadenar al erotismo de esa manera como nos lo hace creer el Otro digital? Precisamente los síntomas en la erótica nos muestran que no es posible, siempre se presenta una fractura. Lo que los síntomas atestiguan es que todos los esfuerzos en digitalizar a Eros fracasan, en el espacio digital también encontramos aquella relación sexual que Lacan declaraba inexistente. Precisamente en la cuestión de los lazos amorosos en el mundo digital el encuentro con el objeto demandado es imposible. Dessal (2019) afirma:

Lo que sí vale la pena señalar, es que la tecnología aplicada a la vida amorosa y sexual introduce -entre otras cosas- una variante cuyos efectos son visibles. Me refiero al hecho de que la posibilidad de someter la búsqueda del partenaire a un procedimiento de filtrado más o menos semejante al de cualquier producto de venta online (color, tamaño, año de fabricación, peso, precio, etc.) permite alimentar la fantasía de "fabricar" a alguien a la medida de nuestros sueños, de encontrar el complemento ideal, un ser que no habrá de decepcionarnos. Aunque no hay nada confiable en el plano estadístico, el psicoanálisis ha descubierto algo cuyas consecuencias son decisivas por cuanto revelan y explican una parte fundamental de las peculiaridades humanas en materia de amor y sexo. Con independencia del curso que siga un encuentro amoroso y sexual, la cita es siempre fallida. Lo es incluso en los casos más felices, aquellos en los que parece haberse conquistado una duradera armonía. La cita es siempre fallida porque entre sujeto y el objeto de su elección existe una fractura inevitable, una inadecuación insalvable. Ningún objeto es capaz de restaurar por completo el mito del paraíso perdido (pp. 36-37). 
Aún con la mensajería instantánea que nos aportan las aplicaciones de WhatsApp, Telegram o Twitter, los usuarios pueden elegir la opción de ocultar su estado en línea o de si han leído los mensajes. Así se frustra la expectativa de lo inmediato, lo que muchas veces ocasiona ofensa, discusiones o la degradación de la vida amorosa. Pero quizás, lo que pone más de manifiesto el síntoma de Eros digital, es que el ser humano no puede ni podría soportar su existencia sin el soporte de artefactos, dispositivos o aplicaciones. La nueva realidad digital también es un lugar donde falta la relación sexual, y eso es precisamente lo que se quiere expulsar en el uso de las nuevas tecnologías para la vida amorosa.

La realidad digital deja poco lugar a la falta, ya que opera en cubrirla constantemente, lanzando al sujeto a un hipertexto infinito de la pantalla global. Si lo que triunfa hoy en día es un eros digitalizado, es por la funcionalidad erótica de los dispositivos y las tecnologías de información. Una funcionalidad que no sería posible entenderla más allá de su consumo, sin los elementos que nos aporta el psicoanálisis en la manera en que las nuevas tecnologías tocan los resortes pulsionales y los aparatos de goce del ser hablante. Y es que las sociedades de la información tienen una función esencial para la economía libidinal del sujeto, ya que esta es la base subjetiva en la que funciona la voraz maquinaria que mueve el sistema de producción y consumo.

\section{Epílogo: ¿Qué lugar para el síntoma?}

Desde sus inicios el psicoanálisis se vincula con la pregunta por el sentido de los síntomas, la razón de su insistencia y su estatuto. Que en el eros digital aparezca el síntoma, nos habla de que algo falla en la aplicación de las nuevas tecnologías a la vida amorosa. Lacan (2009) definía al síntoma como el retorno de la verdad en las fallas de un saber. Ahora bien, el síntoma analítico está hecho de significantes, y para situar al síntoma como verdad a partir del saber, hay que instaurarlo en la cadena significante. Es decir, el síntoma es un efecto de significación, es un efecto del lenguaje. La nueva realidad digital lo que nos presenta son nuevos lenguajes del síntoma. La cuestión que surge es: ¿qué lugar para el síntoma que no sea el de la clasificación, la programación y su 
comercialización? En el ejercicio analítico se tratará de recoger al síntoma en su no-todo irrepetible y peculiar. Como lo señala Allouch (2015) siguiendo una elaboración de Lacan, lo que la experiencia analítica atestigua, es que tenemos que vérnoslas con "verdades indómitas", en la que una de ellas sería la de la "no hay relación sexual", y las otras son las de "no hay Otro del Otro" y "no hay goce del Otro" (p. 124). Precisamente un análisis sería otra manera de vérselas con esas tres maneras confluentes de inexistencia, en donde el sujeto aprende a vivir con las imposibilidades fundamentales que marcan su dimensión amorosa.

\section{Referencias}

Allouch, J. (2015). L'Autresexe, France, Epel.

Byung-Chul, H. (2014). En el enjambre, España, Herder.

Byung-Chul, H. (2021). La sociedad paliativa, España, Herder.

Dessal, G. (2019). Inconsciente 3.0. Lo que hacemos con las tecnologías y lo que las tecnologías hacen con nosotros, España, Xoroi ediciones.

Fernández, E. (2010). $€^{\circledR} 0 \$$. La superproducción de los afectos, España, Anagrama.

Freud, S. (1900). La interpretación de los sueños, en Obras completas, Argentina, Amorrortu, t. IV.

Freud, S. (1914). Introducción del narcisismo, en Obras Completas, Argentina, Amorrortu, t. XIV.

Illouz, E y Kaplan, D. (2020). El capital sexual en la Modernidad tardía, España, Herder.

Lacan, J. (2003). El seminario de Jacques Lacan, La transferencia, Libro 8, Buenos Aires, Paidós.

Lacan, J. (2009). El sujeto por fin cuestionado, en Escritos 1, México, Siglo XXI.

Sibilia, P. (2012). La intimidad como espectáculo, Argentina, Fondo de Cultura Económica.

Ubieto, J (ed.). (2019). Del padre al IPad. Familias y redes en la era digital. [EPub], España, Ned ediciones. 